\title{
La traction animale dans le nouveau contexte des savanes cotonnières du Tchad, du Cameroun et de la République centrafricaine I. Diffusion de la traction animale et sa place dans les exploitations
}

\author{
E. Vall ${ }^{1}$ A.L. Dongmo Ngoutsop ${ }^{2}$ \\ O. Abakar ${ }^{2}$ C. Meyer ${ }^{1}$
}

Mots-clés

Energie animale - Innovation -

Savane - Coton - Tchad - Cameroun République centrafricaine.

\begin{abstract}
Résumé
La traction animale est exploitée depuis très longtemps en Afrique subsaharienne, mais elle a beaucoup évolué. La zone des savanes d'Afrique centrale compte environ 260000 attelages (40 p. 100 d'exploitations équipées au Tchad, contre 25 p. 100 au Cameroun et moins de 10 p. 100 en République centrafricaine). La traction bibovine domine. Dans les systèmes de production, l'énergie animale est utilisée surtout pour le labour à la charrue et d'une manière secondaire pour les opérations d'entretien et le transport. La traction animale a des fonctions agronomiques (mécanisation, intégration agriculture-élevage) et des fonctions socio-économiques importantes. La phase d'équipement est un moment stratégique pour l'exploitation. Depuis 1950, les crédits équipements et l'encadrement technique proposés par les sociétés cotonnières ont fortement contribué au développement de la traction animale. Les paysans ont investi une part importante des revenus du coton dans cette technique.
\end{abstract}

\section{INTRODUCTION}

En Afrique subsaharienne, l'énergie animale est exploitée depuis des siècles pour le transport. La culture attelée est apparue à la fin du XIX ${ }^{\mathrm{e}}$ siècle. Elle a connu un développement vigoureux depuis les années 1950, sous la houlette des projets de développement des cultures industrielles comme le coton et l'arachide. En l'an 2000, dans les pays d'Afrique subsaharienne francophones le cheptel de trait était estimé à 1,4 million de têtes et les équipements agricoles à 2 millions d'unités (17). Dans cette région du monde, on estime que les animaux de trait fournissent environ 10 p. 100 de l'énergie agricole, derrière le travail manuel ( 89 p. 100) et loin devant la motorisation (24).

Dans les zones de savanes d'Afrique centrale, l'énergie animale est employée traditionnellement pour le transport à dos d'âne, de cheval et de zébu. Les premières tentatives de mécanisation de l'agri-

1. Cirad-emvt, TA30/A, Campus international de Baillarguet, 34398 Montpellier Cedex 5, France

E-mail : eric.vall@cirad.fr ; christian.meyer@cirad.fr

2. Irad/Prasac, Station polyvalente, BP 415 , Garoua, Cameroun culture à traction animale datent de la période coloniale. Cependant, la technique n'a connu son véritable essor qu'après la Seconde Guerre mondiale, à partir de 1950, avec la mise en place des filières cotonnières dans le cadre de projets volontaristes encadrés par l'Etat. La traction animale était considérée comme un facteur essentiel pour l'accroissement rapide et l'intensification de la production du coton et des cultures vivrières. Compte tenu de la présence d'un cheptel de zébus disponible localement et de la capacité du cotonnier, plante à enracinement pivotant, à valoriser un travail de préparation du sol relativement profond, les agronomes ont promu l'utilisation de la traction bibovine et de la charrue légère $(2,3,20,31)$.

Peu à peu, dans les zones de plaine où le niveau de pression foncière justifiait le passage à un système agraire plus intensif (réduction de la durée des jachères et amélioration des travaux de préparation et d'entretien des parcelles) et où la situation sanitaire le permettait, les agriculteurs se sont appropriés la technique. On constate que dès les années 1980, elle est devenue une composante essentielle des systèmes de culture et des stratégies des producteurs d'Afrique centrale. Bien que le modèle dominant soit resté celui de la traction bibovine et du labour à la charrue, la pratique 
s'est diversifiée petit à petit avec le développement du transport, des opérations d'entretien mécanique et la diversification des espèces de trait. La culture cotonnière a été le véritable moteur de la diffusion de la traction animale. Mais depuis le début des années 1990, le contexte de développement de la traction animale se modifie, notamment sous l'effet du désengagement progressif de l'Etat du secteur rural.

L'objectif de ce travail a été, dans une première partie, de revenir sur la place, l'histoire et le rôle de la traction animale dans les systèmes de production de la région. Dans une seconde partie, il a été de présenter les recompositions institutionnelles en cours touchant au « marché » de la traction animale, de préciser les nouveaux enjeux liés à l'ensemble des changements et, pour finir, de définir les priorités de la recherche et du développement dans ce contexte en mutation.

\section{REPARTITION ET DIFFUSION}

\section{DE LA TRACTION ANIMALE DANS LA REGION}

\section{Répartition spatiale de la traction animale}

Actuellement, la région compte environ 260000 attelages. Leur répartition est très inégale selon les pays et à l'intérieur des frontières nationales (tableau I). La zone soudanienne du Tchad compte le plus grand nombre d'attelages et les meilleurs taux d'équipements. L'écart n'est pas très marqué entre la préfecture la moins équipée (Logone occidental, 30 p. 100 des paysans propriétaires) et la plus équipée (Mayo-Kebbi, 55 p. 100). Au NordCameroun, environ une exploitation sur quatre possède un attelage. Certaines régions, comme le centre du bassin cotonnier, sont

\section{Tableau I}

Statistiques de la traction animale dans les zones de savanes cotonnières du Tchad, du Cameroun et de la République centrafricaine en I'an 2000

\begin{tabular}{|c|c|c|c|c|}
\hline & Tchad C & Cameroun & Rca & Total \\
\hline Paires de bovins & 160000 & 55000 & 8000 & 223000 \\
\hline Chevaux & 2000 * & 5000 & - & 7000 \\
\hline Anes & 5000 * & * 25000 & - & 30000 \\
\hline Total attelages & 167000 & 85000 & 8000 & 260000 \\
\hline $\begin{array}{l}\text { Taux d'équipement } \\
\text { moyen }\end{array}$ & $40 \%$ & $25 \%$ & $<10 \%$ & $30 \%$ \\
\hline $\begin{array}{l}\text { Département/préfecture } \\
\text { plus équipé(e) }\end{array}$ & e $55 \%$ & $40 \%$ & $0 \%$ & - \\
\hline $\begin{array}{l}\text { Département/préfecture } \\
\text { moins équipé(e) }\end{array}$ & e $30 \%$ & $5 \%$ & $15 \%$ & - \\
\hline
\end{tabular}

* Estimations des auteurs

Sources : Ondr, Sodécoton, Sococa

bien pourvues en attelages, d'autres pas, comme les franges nord et sud de la zone cotonnière. Enfin, en République centrafricaine le nombre d'attelages et les taux d'équipement sont très faibles. Actuellement, la traction animale fait une très nette percée dans les provinces du nord-ouest (Ouham et Ouham-Pendé). Cette répartition spatiale de la traction animale traduit en fait une grande diversité régionale des systèmes agraires (figure 1).

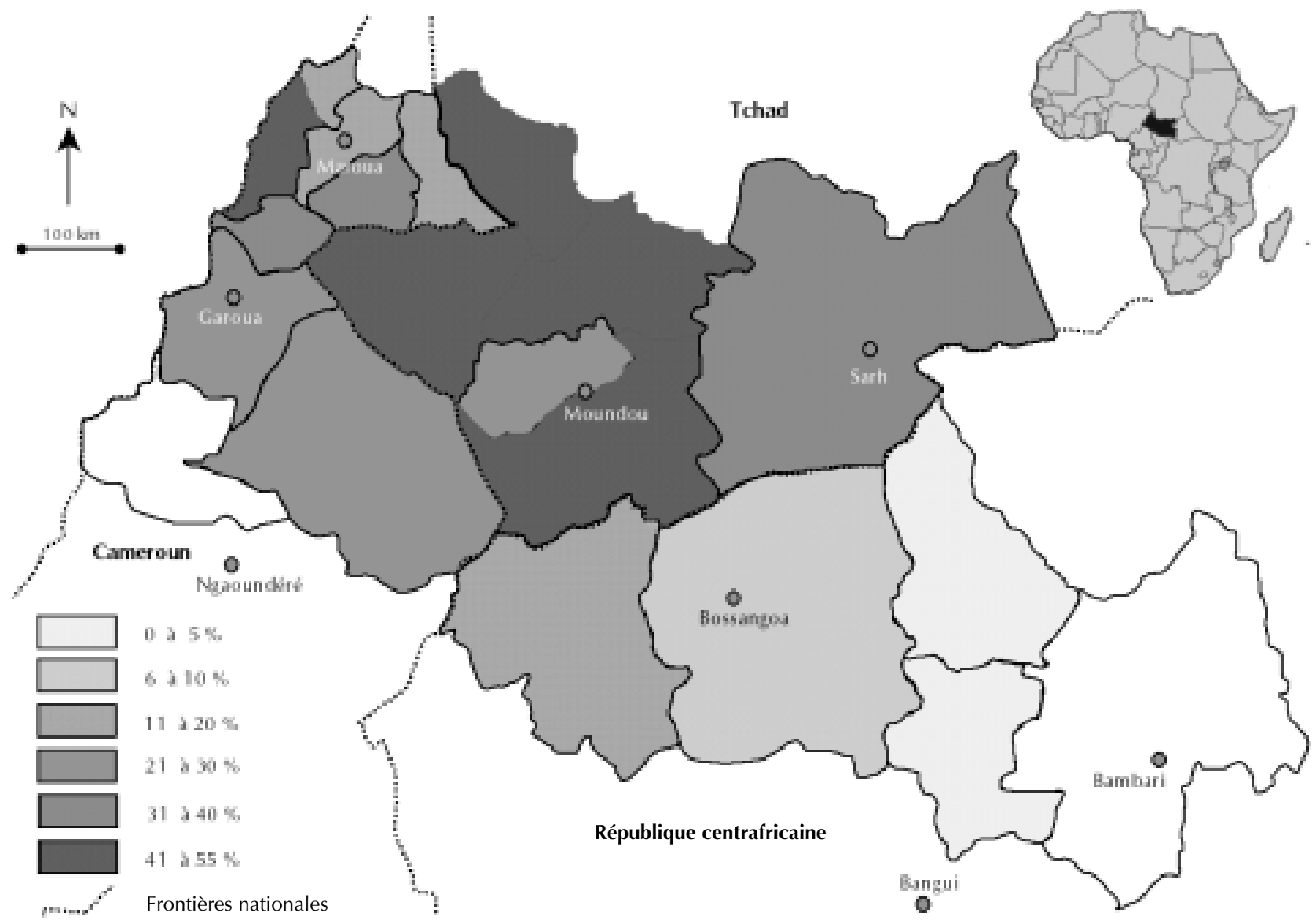

Figure 1 : répartition spatiale de la percée de la traction animale (taux d'équipement en attelage par exploitation agricole) dans les départements du Cameroun et les préfectures du Tchad et de la République centrafricaine (Sources : Ondr, Sodécoton, Sococa, Prasac). 
En République centrafricaine, la traction animale est peu développée. La densité de population est généralement faible (bien souvent inférieure à $5 \mathrm{hab} . / \mathrm{km}^{2}$ ) et, dans cet environnement forestier, les systèmes agraires les plus durables sont de type abatti-brûlis avec jachère de longue durée $(25,38)$. Les pratiques d'exploitation extensives sont plus rentables et n'impliquent pas un investissement visant l'augmentation de la productivité du travail. La culture attelée n'est pas prioritaire pour l'agriculteur. Dans les préfectures les moins habitées, le taux d'équipement est proche de zéro (NanaGrébizi, Kémo, Ouaka). Dans les zones plus peuplées du nordouest $\left(20 \mathrm{hab} . / \mathrm{km}^{2}\right)$, la pression foncière rend nécessaire une évolution du système agraire et la société cotonnière encourage l'extension de la traction animale par des actions de crédit. Les agriculteurs sont demandeurs d'attelages puissants, comme la paire de bovins, en raison de la pression des adventices, mais leurs possibilités financières sont limitées et le manque de fournisseurs d'équipements freine la progression de la traction animale.

Dans le Nord-Cameroun, la traction animale est mieux implantée et les espèces utilisées sont diverses (encadré 1). En moyenne, 85 p. 100 des agriculteurs ont régulièrement recours à la culture attelée et 60 p. 100 grâce aux pratiques de location $(6,8)$. Dans les plaines de l'Extrême-Nord, les densités de population sont élevées (plus de $60 \mathrm{hab} . / \mathrm{km}^{2}$ ) et les jachères ont pratiquement disparu. Les agriculteurs pratiquent un système de culture à base de sorgho pluvial et de coton. La traction animale est utilisée principalement pour le labour des parcelles de coton et concerne peu le sorgho (en dehors du sarclage). Dans les plaines du Nord, les systèmes de culture s'appuient sur trois cultures dominantes l'arachide, le coton et

Encadré 1

Diversité et répARTITION SPATIALE DES ATtelAGES Au NORD-CAMEROUN

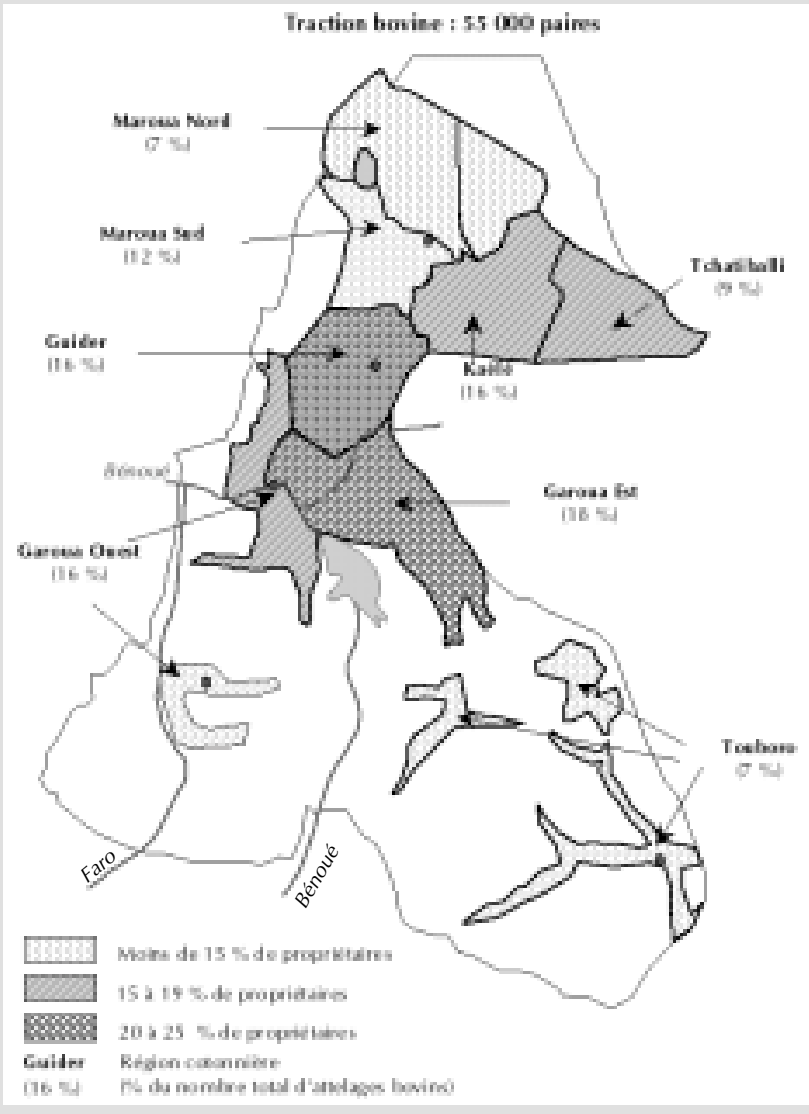

En 1999, le Nord-Cameroun compte 110000 bovins, mâles à 95 p. 100. La race White Fulani (Bororo Akou) domine, suivie de la Red Fulani (Bororo Djafoun). Adultes, les mâles pèsent entre 350 et $500 \mathrm{~kg}$. Historiquement introduite dans l'Extrême-Nord près de Kaélé, la traction bovine reste importante en pays Moundang et Toupouri. Aujourd'hui, elle se développe dans la basse vallée de la Bénoué et autour de Guider.

La traction asine est très présente dans les régions de Guider et de Maroua-Sud qui concentrent 70 p. 100 des effectifs. Dans ces régions, les paysans ont des besoins de traction limités (petites exploitations, pression des adventices moins forte en début de cycle, sols caillouteux...) et des possibilités financières modestes. Au Sud, cette espèce est au contraire peu prisée (manque de puissance, sensibilité à la trypanosomose). Actuellement, on compte

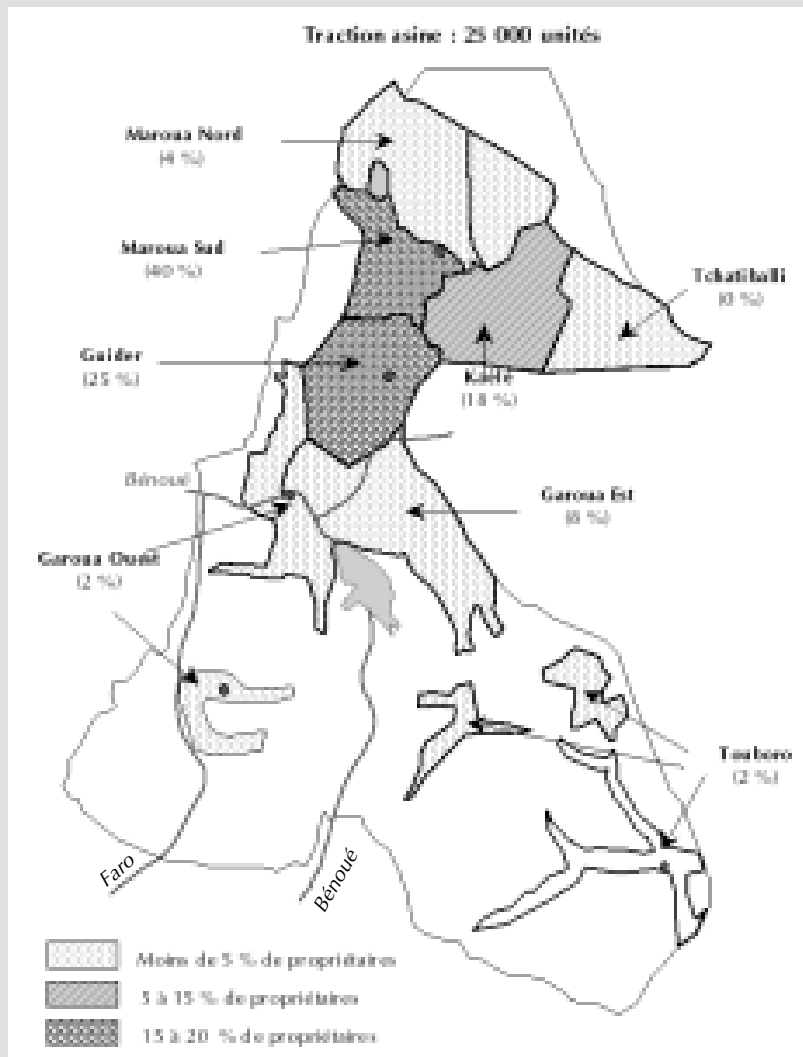

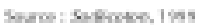

25000 ânes de trait environ. Ils mesurent $100 \mathrm{~cm}$ au garrot et pèsent entre 120 et $130 \mathrm{~kg}$ à l'âge adulte.

Les trois races traditionnelles de grands chevaux, Dongolaw, Barbe et Arabe (250 à $300 \mathrm{~kg}$ de poids vif, 140 à $150 \mathrm{~cm}$ de hauteur au garrot), sont peu recherchées par les paysans qui préfèrent atteler des poneys Museys (poneys du Logone) moins chers, plus rustiques et faciles à entretenir (environ $200 \mathrm{~kg}$ de poids vif). Cette race était en voie d'extinction jusqu'en 1990. Elle connaît désormais un regain sensible, surtout dans I'Extrême-Nord et paradoxalement chez les migrants de la région de Touboro où l'achat d'un poney de trait s'apparente à une stratégie défensive face à la mortalité élevée de bétail.

Sources : Dromard, 1986, Sodécoton ; Ebangi, Vall, 1998, Revue Elev. Méd. vét. Pays trop. ; Seignobos et coll., 1987, lemvt ; Vall, 1996, Cirad-emvt 
le maïs, semées dans cet ordre chronologique. Les paysans utilisent la traction animale sur les trois cultures pour la préparation des parcelles (labour à la charrue) et l'entretien des cultures (sarclage, buttage). Les départements septentrionaux (Diamaré, MayoDanay, Mayo-Sava) et méridionaux (Mayo-Rey, Poli) sont les moins pourvus en attelages. Au Sud, la situation sanitaire du bétail et la concurrence entre les herbicides et le labour mécanique expliquent une percée moyenne de la traction animale. Au nord du bassin cotonnier, peu arrosé (600 à $700 \mathrm{~mm} / \mathrm{an}$ ), le labour à la charrue ne constitue pas une priorité dans des systèmes de production dominés par le sorgho pluvial. C'est une plante que l'on sème sans préparation du sol dès la première pluie utile.

Dans la zone soudanienne du Tchad, la traction animale est très développée et dominée par l'utilisation des paires de bovins (27). Comme au Nord-Cameroun, la pression foncière dans les terroirs a conduit les populations à adopter des systèmes à traction animale légère et des jachères de très courte durée. L'agriculture de la zone soudanienne du Tchad se distingue de celle du Nord-Cameroun par son faible niveau de consommation d'intrants (engrais et herbicides). Aussi, la pratique très répandue des cultures associées entrave la mécanisation des sarclages. Les attelages sont surtout utilisés pour le labour à la charrue, le buttage et le transport à charrette. Les équipements d'entretien sont peu répandus. Pourtant, de l'avis de différents auteurs $(29,34)$, les sarclages constituent un goulot d'étranglement, en grande partie responsable des performances agricoles moyennes enregistrées (coton en moyenne $700 \mathrm{~kg} / \mathrm{ha}$, ensemble des céréales $600 \mathrm{~kg} / \mathrm{ha}$, arachide $700 \mathrm{~kg} / \mathrm{ha}$ ).

\section{Histoire du développement régional de la traction animale}

Dans la zone soudanienne du Tchad, l'appropriation de la traction animale a démarré véritablement au milieu des années 1960 avec la création de l'Ondr ${ }^{1}$ en 1965 , après plus de 15 ans d'opérations d'incitations conduites par le Bdpa ${ }^{2}(11,35)$. A la veille des troubles politico-militaires marquant la fin des années 1970, le Tchad dénombrait 64000 paires de bovins (figure 2). Durant les années de guerre, la production cotonnière s'est effondrée, la traction animale a régressé de 3500 unités environ. Le calme revenu,

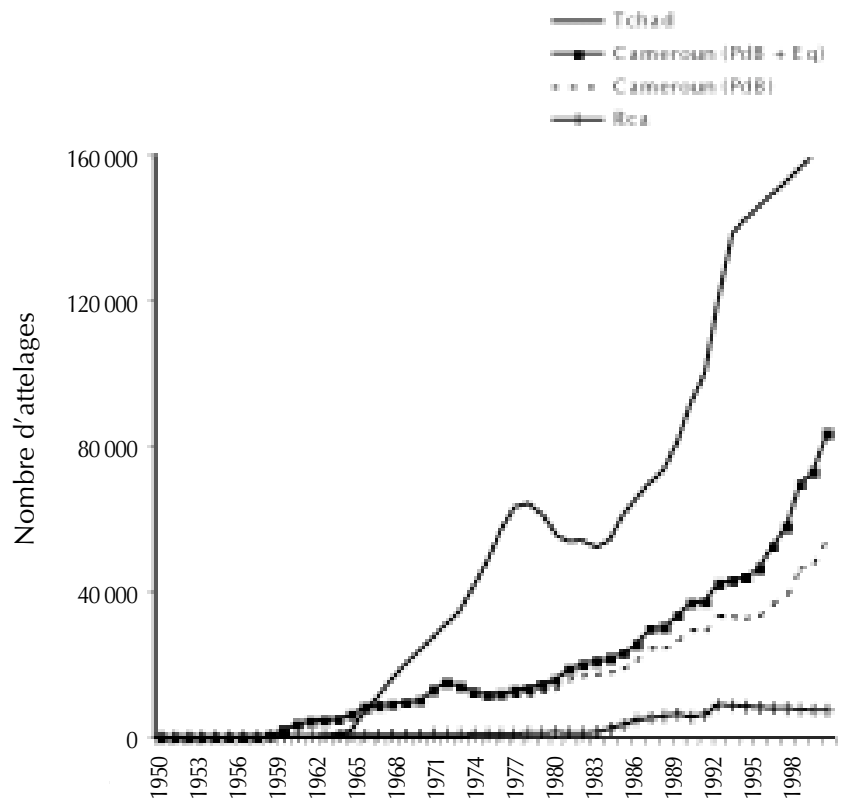

Figure 2 : évolution du nombre d'attelages dans les zones de savanes cotonnières du Cameroun, du Tchad et de République centrafricaine de 1950 à nos jours. $\mathrm{PdB}$ : paire de bovins ; Eq : équins ; sources : Ondr, Sodécoton, Sococa).
l'Ondr a relancé, dès 1986, une opération de crédit et le rythme de l'équipement a repris vigoureusement. La zone soudanienne a atteint 140000 paires de bovins en 1992 (27). Depuis une dizaine d'années, la poussée de l'innovation est moins forte. Le niveau moyen d'équipement de la région s'est rapproché probablement d'un niveau suffisant pour permettre aux non-propriétaires d'accéder à un attelage par la location dans des conditions acceptables de prix et de délais d'attente, ce qui expliquerait en partie le fléchissement observé. Une autre cause du ralentissement est probablement liée à l'offre erratique de matériels. Contrairement au Cameroun, le Tchad a toujours été fortement dépendant des importations en matériels agricoles, surtout depuis la fermeture de la Simat ${ }^{3}$ en 1999. Depuis 1995, l'Ondr lance chaque année un appel d'offres pour s'approvisionner en matériels agricoles. De nombreux dysfonctionnements ont conduit à une offre très irrégulière de matériels et parfois à de véritables pénuries notamment en 1995, 1998, 1999 (statistiques Ondr). Enfin, l'épuisement du fonds de crédit « traction animale » mis en place en 1983 a contribué aussi au ralentissement de la dynamique d'équipement.

$\mathrm{Au}$ Nord-Cameroun, après une phase de développement lente et hésitante de 1950 à $1974(5,14,15)$ sous l'impulsion de la Cfdt ${ }^{4}$ et du Semnord ${ }^{5}$, phase ponctuée par une régression de la traction animale durant les sécheresses des années 1970, le rythme de l'équipement s'est considérablement accéléré depuis le début des années 1980. La Sodécoton ${ }^{6}$ en a fait un des « fers de lance » de l'intensification de la production du coton et des vivriers (31). De 1980 à nos jours, le développement de la traction animale s'est caractérisé par la diversification des attelages et l'enracinement de la pratique (37). Diversification, tout d'abord, avec la progression importante de la traction asine dans l'Extrême-Nord où de nombreux paysans cultivant de petites superficies ( 2 à 3 ha) ont trouvé cet attelage adapté à leurs besoins agricoles et économiques à l'achat comme à l'entretien. Enracinement ensuite car, malgré un taux d'équipement moyen, aujourd'hui 85 p. 100 des paysans ont régulièrement recours à la culture attelée $(6,8)$. Depuis 20 ans, les chocs économiques qui ont touché l'économie du pays et la filière cotonnière n'ont pas affecté le rythme d'appropriation de la traction animale. Il s'est maintenu et tend à s'accélérer depuis 1995 avec 6000 unités de plus chaque année, ce qui laisse à penser que le taux de 40 à 50 p. 100 d'exploitations équipées pourrait être atteint vers 2010. La traction animale est devenue une composante essentielle des stratégies des agriculteurs.

En République centrafricaine, les premiers essais de dressage de zébus Bororo et de taurins importés d'Afrique de l'Ouest dans les années 1950 eurent peu d'impact (23). Les débuts du crédit à l'équipement datent de la fin des années 1960. En 1970, le nombre d'attelages a atteint environ 1500 unités. Durant la réforme agraire de 1971 à 1974, le développement de la traction bovine a été arrêté net au profit de la motorisation. A partir de 1975, le développement agricole a repris sur l'ensemble de la zone cotonnière avec une intensité variable suivant les régions. La traction bovine a diffusé plus vite dans les préfectures du nord-ouest, Ouham-Pendé notamment. Dans ce pays, les matériels ont toujours été importés, principalement du Cameroun, et ont toujours coûté excessivement cher, environ deux fois plus qu'au Cameroun, ce qui a aussi constitué un frein à l'équipement pour les paysans. Aussi, l'artisanat du fer ne s'est jamais développé et les paysans n'ont jamais pu

\footnotetext{
${ }^{1}$ Office national de développement rural

${ }^{2}$ Bureau de développement de la production agricole

${ }^{3}$ Société industrielle de matériels agricoles du Tchad

${ }^{4}$ Compagnie française pour le développement des fibres textiles

${ }^{5}$ Secteur de modernisation du Nord-Cameroun

${ }^{6}$ Société de développement du coton au Cameroun
} 
compter sur cette possibilité. En République centrafricaine, la traction animale a atteint un sommet en 1991 avec près de 9000 paires de bovins. Par la suite, la traction animale a régressé, suite à l'arrêt des crédits et à la fermeture des centres de dressage. Entre 1991 et 1994, le nombre de paires de bœufs a diminué de 12 p. 100, la proportion des charrues hors service est passée de 7 à 22 p. 100 (statistiques de la Sococa ${ }^{7}$ ). En 1995, la Sococa dénombrait à peine 8000 paires de bœufs. En réaction, elle a lancé en 1996 une opération de crédits à moyen terme pour l'équipement. Depuis, les événements politiques ont profondément perturbé l'essor économique de ce pays et de l'agriculture en particulier.

\section{Rôle moteur des cultures industrielles et des services d'appui}

Dans ces trois pays, les revenus du coton relayés par les opérations de « crédit équipements » et de vulgarisation ont largement contribué à l'extension de la technique. Les sociétés cotonnières se sont également appuyées sur des industries locales (Tropic, Manucycle, Simat) et étrangères (Bourguignon, Gouvy...) pour proposer aux producteurs une gamme de matériels certes peu étendue (deux ou trois modèles pour chaque type d'outils) mais de bonne qualité et dont le corollaire a été un prix élevé. Ce lien entre la dynamique cotonnière et la traction animale est parfaitement illustré par le parallélisme des courbes sur la figure 3 .

Le financement de l'attelage a été, et reste, basé sur le revenu du coton (28). Un producteur de coton connait, approximativement, les revenus et les charges de sa culture dès le mois d'octobre, soit environ six mois avant la commercialisation. Il peut concevoir un projet d'équipement et se préparer en conséquence, c'est-à-dire mobiliser, le cas échéant, des ressources financières complémentaires (céréales, animaux, crédit...). Cependant, les systèmes sont peu productifs et les surplus commercialisables sont modestes. Un suivi de plusieurs exploitations agricoles cotonnières modestes du NordCameroun (trois hectares environ) a montré que la capacité d'autofinancement annuelle du ménage agricole dépassait rarement 100000 Fcfa, c'est-à-dire l'équivalent du prix d'un taurillon (40). La superficie moyenne des exploitations de la région étant de 2,5 hectares (16), on comprend la lenteur du processus d'équipement. De telles prévisions sont encore beaucoup plus incertaines lorsqu'il n'existe localement ni culture industrielle, ni filière intégrée.

Dans les zones où l'on pratique une culture industrielle, les seuls systèmes de crédits à l'équipement de masse viables sont ceux

${ }^{7}$ Société cotonnière centrafricaine

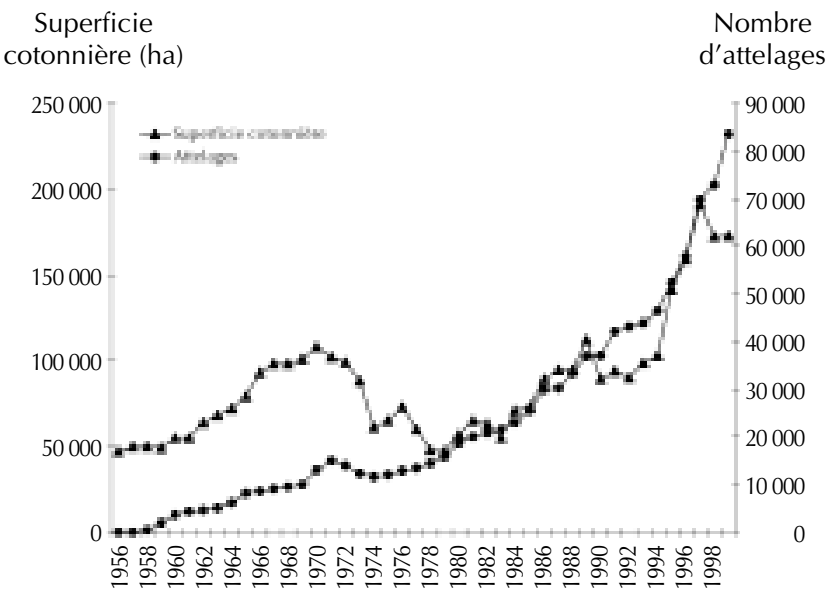

Figure 3 : évolution de la superficie cotonnière $\left(S f_{C}\right)$ et du nombre d'attelages au Nord-Cameroun de 1950 à nos jours (source : Sodécoton). gérés par la société de développement en place (Ondr, Sodécoton, Sococa) en substitution, et parfois en association, à une institution financière. Pour limiter les risques financiers, le prêt ne concerne que l'équipement et jamais l'animal, les annuités sont déduites directement du produit de la culture industrielle. Chaque année, la Sodécoton effectue des crédits à court terme pour le matériel agricole d'un montant compris entre 400 et 700 millions Fcfa (33). Au Tchad, l'Ondr en liaison avec la CotonTchad gère depuis 1983 un fonds annuel de crédit à l'équipement qui s'est élevé initialement à 800 millions de Fcfa par an (39). En 1996, la Sococa a engagé un fonds de 600 millions de Fcfa pour relancer le crédit à l'équipement (38). Malheureusement, au Tchad et en République centrafricaine depuis cinq ans environ, les fonds réellement engagés sont nettement inférieurs aux sommes prévues. Depuis quelques années, dans les trois pays, des services financiers décentralisés (caisses villageoises d'épargne et de crédit, coopératives d'épargne et de crédit, crédit mutuel) expérimentent des formules de crédit $(19,26,39)$. Mais leur offre reste très limitée en raison d'une certaine incompatibilité entre les conditions de crédit proposées (taux d'intérêts élevés) et la rentabilité immédiate de ce type d'investissement.

Le passage de la culture manuelle à la culture attelée nécessite un apprentissage technique important, puisque le paysan adopte un nouveau système de culture qui va profondément agir sur l'organisation de l'activité agricole du ménage, contribuant à la saturation du calendrier agricole. Depuis 50 ans, tous les services de développement se sont beaucoup investis sur les appuis techniques (conduite des animaux, suivi sanitaire, réglages des outils, itinéraires techniques...) ; il paraît superflu d'insister davantage sur cette composante essentielle du développement de la traction animale.

En conséquence, dans les zones où une culture industrielle et des actions de développement coordonnées par une intervention publique sont présentes, la diffusion conséquente de la traction animale est possible à condition que les systèmes agraires se prêtent à l'adoption d'une mécanisation légère à traction animale, ce qui n'a longtemps pas été le cas en République centrafricaine. Aussi, lorsqu'un niveau de diffusion suffisant est atteint, un épisode de crise de la filière industrielle ou bien le désengagement de l'Etat n'entraîne pas un effondrement de la pratique. Peu de paysans sont prêts à abandonner leur attelage pour revenir à la culture manuelle. De plus, dans de telles situations, des acteurs privés se positionnent sur le marché de la traction animale et les paysans eux-mêmes prennent en charge certaines fonctions (apprentissage, dépannage, location...), comme nous le verrons dans la seconde partie.

\section{Importance du suivi sanitaire des animaux de trait}

Dans cette zone majoritairement soudano-sahélienne, caractérisée par une situation sanitaire peu favorable (trypanosomoses, maladies liées aux tiques...), le suivi vétérinaire des animaux de trait a été et reste encore aujourd'hui une composante essentielle pour le maintien de la traction animale.

En République centrafricaine, la Fédération nationale des éleveurs centrafricains (Fnec) avait bien résolu le problème pour l'élevage pastoral avec un service vétérinaire très efficace (3). Malheureusement, les propriétaires d'attelages ayant été très peu représentés dans la fédération, le bétail de trait n'a jamais bénéficié de ce service.

Au Tchad en 1975, les services de l'élevage ont créé les groupements de défenses sanitaires (Gds). Les Gds sont des associations d'agriculteurs prenant en charge les soins des animaux de trait avec l'appui d'une quarantaine d'agents des services de l'Elevage. En 1990 , on dénombrait environ $650 \mathrm{Gds}(22)$. Sous la houlette de la 
privatisation, certains agents de l'élevage sont devenus des mandataires. Mais ils couvrent des superficies importantes et connaissent des difficultés pour approvisionner les producteurs en médicaments. Aujourd'hui, les fonds déposés dans les Gds sont insuffisants pour couvrir les besoins et approvisionner les stocks de médicaments.

Au Cameroun, les services de l'élevage ont toujours ignoré les animaux de trait. Consciente du problème qui se posait, surtout dans le sud du bassin cotonnier, la Sodécoton a créé son propre service élevage en 1978. Aujourd'hui, ce service est coiffé par la Sodécoton et par l'organisation des producteurs de coton (4). La prophylaxie recommandée est axée sur des vaccinations (péripneumonie, charbons et pasteurellose), les déparasitages internes (deux fois par an, au début et à la fin de la saison sèche), la lutte contre les tiques, vecteurs de la dermatophilose (applications de produit pour-on en saison des pluies), et la lutte contre les trypanosomes (chimiothérapie adaptée selon les zones à risques). Le coût d'une prophylaxie minimale est estimé à $7600 \mathrm{Fcfa}$ par bovin adulte et par an. Cette norme est loin d'être atteinte. Dans le sud du bassin cotonnier, les dépenses effectives des paysans s'en approchent en raison d'une pression sanitaire plus forte (7 000 Fcfa par an). Dans les autres régions, on en est loin et les dépenses diminuent plus on progresse vers les zones arides (3 500 Fcfa à Garoua, 2000 Fcfa à Guider, 1000 Fcfa à Maroua).

Dans le domaine de la santé, même si aujourd'hui les trypanosomoses sont en net repli, suite aux défrichements agricoles des populations qui s'installent en zone soudanienne, des progrès sont encore possibles pour réduire la mortalité (qui s'élève à environ 10 p. 100 pour les bovins) et la morbidité du bétail (plaies dorsales de dermatophilose aggravées par le joug, parasitoses gastro-intestinales...).

\section{- PLACE DE LA TRACTION ANIMALE DANS LES EXPLOITATIONS AGRICOLES}

Les producteurs de la région dirigent le plus souvent des exploitations familiales dont la superficie cultivée est comprise entre 1 et 15 hectares (16). Pour ces hommes et ces femmes, l'énergie animale est un auxiliaire déterminant pour augmenter la productivité par actif et diversifier les sources de revenus. Dans les systèmes marqués par la disparition de la jachère et l'intensification par le travail, la culture attelée facilite la maitrise des adventices, agit sur la gestion de l'eau à la parcelle et, grâce à la fumure animale, contribue modestement à l'entretien de la fertilité. L'énergie animale permet l'augmentation de la surface cultivée par unité de production. Mais l'accès à un attelage pose encore beaucoup de difficultés à de nombreux paysans.

\section{Phase d'équipement}

\section{Moment stratégique dans la vie de l'exploitation}

Le passage de la culture manuelle à la culture attelée ou encore l'acquisition d'un nouvel attelage sont toujours associés à une stratégie de financement et à un projet de l'agriculteur à moyen terme (extension de la surface cultivée, diversification des productions et des activités...). Aussi, pour l'agriculteur, le choix de l'attelage met en jeu des éléments techniques, économiques et stratégiques en interaction comme l'indique la figure 4.

Les principaux éléments techniques pris en compte sont les conditions locales d'enherbement, le type de sol (lourd, léger...) et l'environnement parasitaire (glossines, tiques...). On peut constater qu'ils sont tous largement influencés par les conditions climatiques. Ces éléments vont jouer sur le choix de l'espèce animale (adaptation aux conditions environnementales, capacités de travail...) et sur le choix des caractéristiques des équipements (charrues lourdes, légères...). Aujourd'hui ces éléments techniques et les critères de conformation des animaux pour le travail (aplombs...) sont bien maîtrisés par les paysans (37). On peut s'étonner toutefois, d'une part, d'un certain conformisme des agriculteurs qui placent généralement en priorité l'achat d'une paire de bovins quelle que soit la taille de leur exploitation et, d'autre part, du manque de vision progressive sur l'équipement (beaucoup de paysans s'estiment suffisamment équipés avec seulement une charrue...).

Les éléments économiques pris en compte par l'agriculteur sont principalement la capacité d'autofinancement ainsi que la recherche d'une meilleure rentabilité de l'activité agricole. La capacité d'autofinancement du producteur dépend des résultats économiques du système de production (équilibre recettes/dépenses, performances techniques...), de l'habileté de l'agriculteur à gérer les différentes formes d'épargne domestiques, de son aptitude à mobiliser des aides au financement et de sa faculté à contrôler les dépenses non prioritaires. Mais plusieurs études ont montré que les paysans ont une représentation assez vague du fonctionnement économique de leur exploitation. Dans leurs pratiques de gestion, l'incertitude prédomine ; la prévision et l'avenir sont rarement envisagés au-delà d'une campagne (7). Pour les agroéconomistes aussi, cet aspect du fonctionnement économique de l'exploitation (pratiques de gestion de trésorerie, pratiques d'épargne...) reste méconnu (30). La capacité d'autofinancement se résume bien souvent à ce qui reste de l'argent du coton après le règlement des nombreuses dettes, plus l'argent du reliquat de céréales non consommées durant la saison sèche. L'amélioration de la rentabilité de l'activité agricole est difficile à quantifier et les agriculteurs ont des difficultés à exprimer leurs attentes dans ce domaine. En général, ils citent (par ordre d'importance décroissant) l'augmentation de la surface cultivée, de meilleurs rendements, et une meilleure intégration agriculture élevage génératrice de revenus directs et indirects.

Les éléments stratégiques représentent les projets de l'agriculteur. Ces derniers dépendent de la situation du producteur et des objectifs visés à moyen terme. La disponibilité locale en terres agricoles et la possibilité de mobiliser de la main-d'œuvre agricole supplémentaire sont deux éléments déterminants du projet d'équipement dans une perspective de rentabilisation. Mais les agriculteurs ont beaucoup de difficultés à se projeter dans l'avenir compte tenu des nombreuses incertitudes auxquelles ils sont confrontés (prix, pluie...) et de leur manque d'information. Il est toujours très difficile de les faire s'exprimer sur ce qu'ils attendent d'un attelage et en quoi cela va changer leurs conditions de travail et les performances technico-économiques de l'exploitation.

Le choix d'un attelage est encore subordonné à des facteurs socio-économiques, comme les tabous et les usages coutumiers,

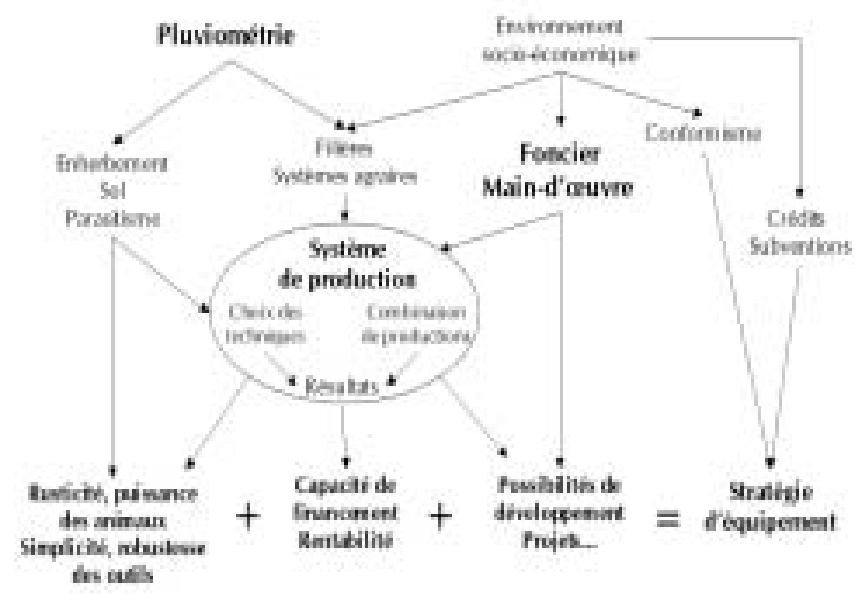

Figure 4 : éléments pris en compte lors du choix d'un attelage. 
les phénomènes de suivisme, la politique agricole... Notons enfin que les opportunités d'aide au financement (crédits, subventions) peuvent jouer un rôle décisif sur la décision finale de l'agriculteur et le faire opter pour un choix contraire à une logique purement technique.

\section{Période difficile pour le producteur}

Les producteurs ont des difficultés à dégager les fonds nécessaires au financement d'un attelage sur le revenu agricole. Aujourd'hui, il n'y a pratiquement que les sociétés cotonnières et l'Ondr qui proposent des crédits pour les équipements. De plus en plus de producteurs sont à la recherche d'outils bon marché et se fournissent chez les artisans forgerons (18). Pour l'animal, ils doivent compter sur leur capacité d'autofinancement qui dépend en grande partie du revenu du coton (28). Le plus souvent, ils achètent directement leurs animaux chez un éleveur, parfois sur les marchés (6). Ils le prélèvent rarement sur leur troupeau, bien souvent faute d'avoir un troupeau. L'opération se fait généralement après le paiement du coton (donc au cours du premier trimestre de l'année civile) et requiert presque toujours un complément financier apporté par la vente de céréales (40). Un schéma d'équipement maintes fois rencontré dans la région de Garoua est décrit à titre d'illustration dans l'encadré 2.

Aujourd'hui, la pression foncière s'accroît dans de nombreuses zones agricoles. Lorsqu'un certain niveau est atteint, le développement des exploitations agricoles ne peut plus se faire par une extension de la surface cultivée. Dans ces conditions, les jeunes qui s'installent ont des difficultés à constituer une réserve foncière suffisante. Pour eux, l'investissement dans un attelage lourd et coûteux, comme la paire de bœufs, fait peser sur leurs épaules un risque élevé de surendettement. Avec eux, il faut repenser totalement les stratégies d'équipement et proposer des outils de conseil et des aides au financement prenant en compte leur situation et leurs projets à moyen terme, de manière à ce qu'ils puissent s'orienter vers un équipement adapté à leurs besoins (40).

\section{Fonctions agronomiques}

\section{Mécanisation des systèmes de culture}

L'attelage peut être utilisé à toutes les étapes du calendrier agricole (9). Dans cette région à pluviométrie comprise entre 700 et $1500 \mathrm{~mm}$ par an, la traction animale est principalement utilisée dès le retour des premières pluies utiles pour la préparation des parcelles de coton, de maïs et d'arachide au moyen du labour à la charrue (encadré 3). Cette opération permet le décompactage du sol et l'enfouissement de la matière organique et des mauvaises herbes (42). Dans les zones peu arrosées, les agriculteurs ont recours à des attelages légers, comme les ânes de trait et effectuent un travail du sol superficiel (8). Dans les zones plus humides, la pression des adventices est forte, le labour requiert une puissance importante, les paysans préfèrent les paires de bovins. Au NordCameroun, grâce à la Sodécoton qui a vulgarisé l'utilisation des herbicides, les paysans parviennent à réduire les travaux de préparation du sol. Depuis quelques années, la demande des agriculteurs se porte de plus en plus sur les charrues légères ( 9 pouces), car l'utilisation des herbicides n'exige plus le même travail d'enfouissement des adventices.

Aujourd'hui, le taux d'équipement en charrues atteint bien souvent un niveau suffisant pour que les priorités des paysans se reportent sur l'acquisition de matériels d'entretien. Au Cameroun, depuis quelques années, les ventes de sarcleurs et de corps butteurs prennent l'ascendant sur les ventes de charrues (statistiques de la Sodécoton). Au Tchad, les butteurs se vendent plus que les sarcleurs (statistiques de l'Ondr). Bien que la mécanisation des opérations d'entretien des cultures progresse, elle reste loin derrière le labour

\section{Encadré 2}

\section{SCHÉMA D'ÉQUIPEMENT SOUVENT DÉCRIT DANS LA RÉGION DE GAROUA}

Lorsqu'un jeune agriculteur s'installe, ses revenus sont souvent insuffisants pour acquérir un attelage. Ses efforts se portent sur I'acquisition de parcelles, sur le règlement de la dot grâce au revenu d'activités extra-agricoles et de cultures peu exigeantes en intrants (arachide...). Après quelques années, lorsqu'il s'est constitué une réserve foncière de deux à trois hectares, sa capacité d'autofinancement lui permet d'envisager l'achat d'un taurillon (80 000 à $100000 \mathrm{Fcfa}$ ), au prix d'économies sévères sur les autres dépenses du ménage. La constitution d'une paire complète prend alors deux à trois années. Certains s'associent pendant cette période de transition pour constituer une paire de bœufs. Durant la phase d'équipement, l'agriculteur augmente la part du coton dans son assolement. Dans les années qui suivent l'acquisition de I'attelage, on constate une nouvelle augmentation de la réserve foncière, mais elle reste toujours proportionnée à la possibilité de mobiliser une main-d'œuvre agricole suffisante pour les opérations d'entretien et pour les récoltes.

Source : Cuvier, 1999, Cirad-emvt

à la charrue. Le Cameroun et le Tchad ne dénombrent respectivement qu'un ensemble sarcleur pour 4 et 14 charrues $(27,33)$. Avant la mécanisation, les semis de céréales (mil, sorgho) et de légumineuses (niébé, arachide) étaient effectués précocement sans travail du sol important, les adventices étant éparses au démarrage des pluies. L'introduction de nouvelles plantes cultivées (coton, maïs...) a allongé la période des semis en raison des exigences de culture de ces plantes, rendant nécessaire une préparation du sol au moyen du labour pour enfouir les adventices et la matière organique et ameublir le sol. Mais, la pénibilité du labour manuel a limité l'extension des surfaces cultivées. L'attelage et la charrue ont levé cette contrainte. Durant les 40 premières années de développement de la traction animale, l'attrait des paysans pour la culture attelée a d'abord porté sur la mécanisation du labour à la charrue. La traction animale est entrée dans les systèmes de culture d'abord par les opérations exigeant le plus d'énergie agricole et le moins de technicité. Depuis une dizaine d'années, les paysans mécanisent de plus en plus les chantiers d'entretien (sarclage et buttage). Certains voient dans ces techniques la possibilité de desserrer les contraintes de main-d'œuvre dans le calendrier agricole. D'autres, placés sous contrainte de pression foncière, optent pour ces techniques afin d'améliorer leur production sur une surface cultivée limitée. Aujourd'hui, la traction animale progresse par de telles pratiques, plus exigeantes en technicité (respect des semis en lignes et des dates d'intervention...), mais plus économes en énergie de traction.

\section{Intégration agriculture-élevage et conduite des animaux de trait}

L'intégration agriculture-élevage correspond à une forme d'intensification basée sur une gestion raisonnée des flux de matière organique et d'énergie disponibles sur les terroirs et les exploitations. A l'échelle individuelle, l'attelage est un maillon essentiel de l'intégration par son apport d'énergie agricole et pour le recyclage des résidus de culture. Elle s'appuie sur un mode de conduite des animaux de trait en stabulation. Promu puis critiqué par les agronomes et les zootechniciens (21), le modèle techniciste s'est brisé sur la réalité socio-économique des exploitations (charges de travail largement sous-estimées, rentabilité économique et capacités financières des paysans surévaluées). En définitive, on constate que les paysans ont développé des modalités d'intégration de l'agriculture et de l'élevage mettant en jeu des pratiques collectives qui prennent 


\section{Encadré 3}

\section{Culture attelée au Nord-Cameroun}

\section{Labour}

Avec le labour, l'objectif poursuivi par les paysans est la préparation d'un lit de semences dégagé d'adventices et décompacté en surface pour favoriser la pénétration des pluies et la germination rapide des graines. Le labour est effectué après la première ou la seconde pluie utile, juste avant le semis. Le travail du sol est inférieur à $15 \mathrm{~cm}$, avec des sillons disjoints. Les bovins sont attelés à des charrues 9 ou 11 pouces et les ânes à des charrues 7 pouces. Les parcelles mesurent généralement moins de $100 \mathrm{~m}$ ce qui occasionne de fréquents demi-tours en fin de raie. Ceci conduit les agriculteurs à se défaire de la roulette qui alourdit le maniement de l'outil et incline leur préférence pour les matériels légers (charrue 9 pouces). Le cotonnier bénéfice le plus du labour à la charrue (70 p. 100 de la surface cotonnière), suivi du maïs et de l'arachide. Les premiers semis (mils, sorgho djigari) sont presque toujours effectués sans labour préalable. Dans le sud du bassin cotonnier, de plus en plus de paysans remplacent le labour mécanique par un désherbage à I'herbicide (glyphosate). Ce type de semis direct est appelé localement le « labour chimique ».

\section{Sarclage}

Dans le calendrier agricole de début de saison, le labour et le semis sont toujours prioritaires sur le premier désherbage. Certains paysans fractionnent le semis du sorgho en deux vagues pour étaler les premiers sarclages. Compte tenu de l'incertitude sur la pluviométrie à venir, la stratégie des paysans consiste à semer le plus de surface possible quitte à en abandonner une partie plus tard. Quelle que soit la culture, le premier sarclage est tardif (25 à 30 jours après le semis). A partir de cette date, le désherbage constitue un goulot d'étranglement majeur dans les calendriers agricoles des exploitations. En général, le coton et le maïs sont sarclés deux fois, puis buttés. L'arachide est sarclée une fois, parfois deux. Le sorgho n'est sarclé qu'une seule fois. Faute d'équipement, la majorité des sarclages sont effectués à la main. II faut compter 25 à 35 jours par hectare par personne. Les chantiers avancent lentement, ce qui entretient les désherbages tardifs avec pour conséquences des pertes de production importantes (concurrences culture/adventices) et des abandons de parcelles envahies par les adventices. La mécanisation du désherbage, en réduisant significativement la durée d'intervention, pourrait contribuer à résorber le problème. Mais les raisons du maintien du désherbage manuel sont nombreuses (multifonctionalité, coût de l'équipement, pratiques des cultures associées, défauts de certains outils...). Certains agriculteurs sarclent à la charrue en effectuant deux passages par sillon.

\section{Buttage}

Avec le buttage, trois objectifs sont poursuivis : i) éviter les excès d'eau au cours du cycle, ii) désherber et iii) recouvrir l'urée épandue juste avant. La Sodécoton recommande de butter entre 30 et 40 jours après la levée. C'est une pratique qui concerne surtout le sud du bassin cotonnier, plus arrosé, où l'emploi d'urée et un désherbage à 40 jours se justifient plus que dans l'Extrême-Nord.

Sources : Aboubakary, 2001, Fasa ; Tchinsahbe Pabame, 2002, Fasa ; Vall, Huguenot, 2001, Columa ; Vandendael, 2000, FusaGx en compte leur force de travail et leur capacité financière. Ils se sont appuyés sur la mobilité des animaux pour les conduire à la ressource et non l'inverse. Ils ont recours à des pratiques individuelles ou collectives visant à réduire les charges de travail comme la vaine pâture, les troupeaux villageois, les contrats de fumure, la constitution de meules de paille au champ protégées par des épines (12). Les stocks fourragers sur l'exploitation sont limités et servent d'appoint en fin de saison sèche. La fumure animale est principalement épandue sur les champs de case. Notons que, dans les zones semi-arides, du fait de la rareté des ressources, les pratiques d'intégration sont plus développées qu'en zone soudanienne. Il en va de même lorsque la pression foncière augmente.

Aujourd'hui, le dressage ne pose plus de véritable problème. Le gardiennage est fréquemment résolu par la constitution d'un troupeau de village gardé par un berger. La nuit, les animaux sont placés à l'intérieur des concessions familiales. Les dépenses d'alimentation se résument souvent à l'achat de deux sacs de tourteau de coton par an, distribués en fin de saison sèche. Dans les zones arides, les producteurs couvrent d'épineux les meules de pailles de céréales confectionnées sur les parcelles et font pâturer les animaux au champ.

\section{Fonctions socio-économiques}

L'adoption de la traction animale renforce la composante élevage de l'exploitation, ce qui pour le ménage agricole a des incidences multiples sur les performances technico-économiques, sur l'organisation du travail (tâches supplémentaires liées au gardiennage et à l'entretien des animaux), sur les dépenses (alimentation, santé et garde des animaux), mais aussi sur les revenus (plus-value à la réforme, prestations de services). Dans les villages, la diffusion de la technique a eu des incidences sur l'évolution des rapports sociaux.

\section{Effets sur la productivité du travail}

L'énergie animale permet, en général, une augmentation de la productivité du travail sur l'exploitation qui se traduit par une augmentation de la surface cultivée par actif. Le tableau II rassemble les résultats de plusieurs enquêtes menées ces dix dernières années au Tchad, au Cameroun et en République centrafricaine. Si l'effet de la traction animale est bien marqué au Cameroun et en République centrafricaine, il ne ressort pas au Tchad. Un travail de vérification d'une telle situation mériterait d'être conduit dans ce pays. L'augmentation de la productivité du travail a pour corollaires :

- une augmentation significative de la surface cultivée de l'exploitation (16), si la pression foncière le permet et si le producteur parvient à augmenter le nombre d'actifs (à niveau de main-d'œuvre équivalent, les exploitations équipées sont plus grandes) ;

- une réduction de la pénibilité de certains travaux, notamment ceux très exigeants en énergie agricole (préparation du sol, entretien, transport) et une augmentation de la vitesse de travail. La mécanisation du désherbage du cotonnier divise par trois la durée de l'intervention à l'hectare (41) ;

- une nette augmentation de la charge globale de travail sur l'exploitation liée à l'extension des surfaces (report des pics des travaux sur les chantiers d'entretien pouvant conduire à la gestion d'une maind'œuvre d'appoint), à l'alimentation et au gardiennage des animaux (dressage, conduite au pâturage, stockage d'aliments...).

\section{L'attelage, source de revenus directs et indirects}

Au Nord-Cameroun, un taurillon qui coûte $90000 \mathrm{Fcfa}$ à trois ans peut être revendu cinq ans plus tard à 180000 Fcfa pour des dépenses annuelles d'entretien de $10000 \mathrm{Fcfa}$, ce qui donne une plus-value à la réforme de $40000 \mathrm{Fcfa}$. Malgré de possibles interruptions de carrières accidentelles liées au vol ou à la maladie, la majorité des producteurs réalise un bénéfice à la revente des 


\section{Tableau II}

Actifs, surfaces cultivées et surfaces cultivées par actif en fonction du niveau d'équipement dans les savanes cotonnières du Tchad, du Cameroun et de la République centrafricaine

\begin{tabular}{llcccc} 
Pays & Niveau d'équipement & Actifs & $\begin{array}{c}\text { Surface cultivée } \\
\text { (ha) }\end{array}$ & $\begin{array}{c}\text { Surface/actif } \\
\text { (ha) }\end{array}$ & Sources \\
\multirow{3}{*}{ Tchad } & Manuels et locataires & 2,5 & 2,3 & 0,9 & Enquête Ondr (1992), \\
& Laboureur bovin & 4,2 & 4,0 & 0,9 & 480 exploitations \\
& Lab. bovin + charrette & 5,0 & 4,7 & 0,9 & Base de données \\
\multirow{3}{*}{ Cameroun } & Manuel & 1,9 & 0,9 & 0,4 & Irad/Prasac (2000), \\
& Locataire d'attelages & 2,6 & 1,6 & 0,7 & 900 exploitations \\
\multirow{3}{*}{ Rca } & Laboureur asin & 4,1 & 2,9 & 0,8 & Enquête Icra (1995), \\
& Laboureur bovin & 4,1 & 3,8 & 1,0 & 988 exploitations
\end{tabular}

animaux $(6,28)$. En général, le cheval et l'âne ne procurent pas de telles perspectives économiques.

Les revenus tirés de la location constituent un appoint non négligeable, cependant insuffisant pour rentabiliser l'investissement. A titre indicatif citons quelques tarifs pratiqués par les propriétaires d'attelage : 15000 à 20000 Fcfa par hectare labouré ; 500 à 2000 Fcfa par charrette selon la quantité transportée et la distance. Dans les zones peu équipées, le marché de la location est très actif, puis il décroît lorsque le niveau d'équipement augmente. D'après certaines observations, il s'éteint progressivement lorsque 40 p. 100 des producteurs sont propriétaires d'un attelage $(6,8)$.

\section{Transport attelé et portage}

Les attelages sont aussi utilisés pour le transport. Au Tchad, le transport attelé est bien développé, avec environ 35000 charrettes, et très actif durant la saison sèche. Principalement utilisée pour le transport de la récolte du coton, la charrette est aussi employée pour les besoins domestiques (eau, matériaux de construction...) et les mises en marché. Dans ce pays, l'enclavement des campagnes et l'indigence des services de transport ont probablement incité les paysans à investir dans une charrette et ce, malgré le prix peu attractif des matériels proposés. Il se peut aussi que les crédits à l'équipement aient contribué à cet engouement des paysans pour la charrette. Avec seulement 5000 charrettes bovines, le Cameroun est peu équipé puisque cela ne fait qu'une charrette pour 70 producteurs de coton. Dans ce pays, la multiplication des points de collecte du coton, la circulation des taxis-brousse dans les campagnes reculées et, par endroits, un relief très accidenté peuvent expliquer le désintérêt des paysans pour la charrette et leur attrait pour le pousse-pousse dans les transports de proximité. Les éleveurs transhumants utilisent des ânes et des bovins porteurs lors de leurs déplacements. Les agriculteurs bâtent les ânes à cru, ce qui occasionne de fréquentes plaies dorsales.

\section{Impact sur les rapports sociaux dans les villages : le cas des villages de migrants}

Cette section traite du cas du village de Mafa Kilda, proche de Garoua, créé il y a quelque vingt années par des migrants Mafa en provenance de l'Extrême-Nord (6). Par rapport à l'accès à la traction animale, on distingue trois catégories d'exploitations : les laboureurs, les locataires et les bouviers. Dans ce village, la diffusion de la traction animale s'est accompagnée de l'apparition d'une classe d'exploitants que l'on peut qualifier de laboureurs (propriétaires d'attelages). Ce sont en général les premiers arrivants et ils représentent aujourd'hui 30 p. 100 des exploitations. Les laboureurs, en partie grâce à leur attelage, ont étendu les surfaces cultivées et petit à petit concentré dans leur main la majorité de la réserve foncière du finage, puisque l'usufruit d'une terre revient à celui qui la travaille. Ils sont installés sur les meilleures terres, dirigent les plus grandes exploitations et sont proches ou impliqués dans la chefferie. D'une certaine manière, ces grands agriculteurs contrôlent le foncier (ils ont l'usufruit de 70 p. 100 des terres du village) et la traction animale. Cependant, ils ont besoin de main-d'œuvre agricole pour mettre en valeur leur exploitation au moment des labours, des sarclages et des récoltes (tableau III).

\section{Tableau III}

Statistiques sur les trois types d'exploitations de Mafa Kilda classées par rapport à leur type d'accès à la traction animale

\begin{tabular}{lccc} 
Statistiques par type & Bouviers & Locataires d'attelages & Laboureurs \\
\hline Nb. d'exploitations & 46 & 63 & 45 \\
Nb. d'actifs & 111 & 155 & 181 \\
Réserve foncière (ha) & 29 & 90 & 266 \\
Surface cultivée (ha) & 71 & 105 & 237 \\
Surface cultivée/exploitation (ha) & 1,5 & 1,7 & 5,2 \\
Surface cultivée/actif (ha) & 0,6 & 0,7 & 1,3
\end{tabular}

Source : base de données exploitations Irad/Prasac 
Les locataires accèdent à la traction animale par la location d'attelage. Ils forment la seconde vague d'immigration et sont très nombreux (41 p. 100 des cas). En moyenne, leur exploitation est de taille modeste et ces agriculteurs louent très peu de terres aux laboureurs. La location est une pratique qui permet d'accéder à la traction animale dans des conditions satisfaisantes de délais d'attente et de prix si le niveau d'équipement local est suffisant (plus de 25 p. 100 de propriétaires d'attelages). Ils travaillent souvent dans les champs des laboureurs au moment des sarclages pour gagner de l'argent et parfois pour payer la location de l'attelage. Leur souhait est d'acquérir un attelage, mais leur stratégie est souvent bloquée par le manque de terre disponible.

On trouve enfin des bouviers qui sont de jeunes paysans très liés aux laboureurs, notamment par la parenté, installés depuis peu dans le village. Ils conduisent l'attelage du laboureur sur ses parcelles et chez les locataires d'attelages et, en contrepartie, ont un droit d'usage de l'attelage selon les termes d'un contrat passé avec le laboureur (en général un jour après trois jours de travail pour le patron). Le patron leur accorde un petit lopin de terre qui constitue l'embryon de leur exploitation. Mais 59 p. 100 des terres qu'ils cultivent appartiennent à des laboureurs de Mafa Kilda et des villages voisins. Leur chance de constituer une grande exploitation est très faible dans la mesure où l'espace agricole est déjà distribué entre les deux autres classes.

Ce schéma paraît assez caractéristique des villages de fronts pionniers cotonniers et met en avant le rôle de la traction animale dans la stratégie de conquête foncière des migrants. Il se décline différemment dans les zones d'émigration situées plus au nord. Dans ces zones où la traction animale a commencé sa diffusion dans les années 1950, les études que nous avons conduites n'ont pas révélé l'existence de tractations comparables sur les terres et les attelages entre exploitations, ce qui est certainement lié à l'histoire des terroirs et à une distribution des terres très ancienne qui a largement précédé l'apparition de l'attelage. Les prêts de terres et d'attelages se font surtout entre membres d'une même famille et engagent rarement de l'argent (8).

\section{- CONCLUSION DE LA PREMIERE PARTIE}

Après 50 années de développement dans les savanes cotonnières d'Afrique centrale, la traction animale occupe une place centrale dans les stratégies individuelles et collectives des producteurs, notamment dans les zones où le niveau de pression foncière a justifié l'adoption d'un système agraire à culture attelée légère avec jachère de courte durée afin d'améliorer les travaux de préparation du sol et d'entretien des cultures. Sur les fronts pionniers cotonniers, généralement peu peuplés, elle est un élément central de la stratégie des migrants qui visent une conquête rapide de terres agricoles. D'une façon générale, en augmentant la productivité par actif, elle a contribué à l'accroissement de la surface cultivée par exploitation.

Dans cette région, les paysans préfèrent les paires de zébus. Au Nord-Cameroun, l'âne de trait occupe une part de plus en plus importante surtout dans les zones moins arrosées et parmi les agriculteurs modestes. Le cheval, malgré son importance culturelle, reste marginal. La situation physiologique des animaux est loin d'être misérable, comparativement aux cas rencontrés dans les zones plus arides. Cependant, des progrès sont souhaitables dans le domaine de la santé. L'utilisation des animaux de trait progresse peu à peu vers d'autres pratiques que le labour à la charrue. Mais, cette évolution est loin d'être achevée notamment pour le transport, le sarclage et la diversification des attelages. L'intégration agriculture-élevage reste assez frustre (pas de vaches, faible valorisation du fumier...) et pourtant, l'amélioration significative de cette intégration semble bien être une des clés pour l'évolution des systèmes mixtes. La paire de zébus joue un rôle économique central dans l'économie des ménages en tant que source de revenus (surtout à la réforme) et d'élément de capitalisation et d'épargne. La multifonctionalité du bovin de trait est très certainement à l'origine de son succès dans cette région et plus généralement en Afrique subsaharienne.

Le moteur du développement de la traction animale a été et reste la culture cotonnière avec l'ensemble des services attachés à cette filière (crédits d'équipement, vulgarisation, encadrements vétérinaire et zootechnique). Certaines contraintes qui dans le passé ont pu freiner son développement, surtout dans la partie soudanienne (insuffisance du cheptel disponible, trypanosomoses...), sont en net recul en raison de l'installation d'une population de plus en plus nombreuse d'agriculteurs et de l'importance prise par l'élevage dans les zones subhumides. D'autres contraintes, comme le financement de l'attelage et son entretien (suivi sanitaire, entretien des équipements...), se posent toujours au producteur, mais d'une tout autre manière car l'environnement institutionnel est en pleine mutation avec le désengagement progressif de l'Etat des filières cotonnières et du secteur rural. De nouveaux acteurs se positionnent sur le «marché » de la traction animale. La deuxième partie envisagera ces évolutions et le rôle que la recherche devrait jouer pour le développement.

\section{BIBLIOGRAPHIE}

1. ABOUBAKARY, 2001. Comparaison des performances au champ, sur cotonnier, de deux outils de sarclage mécanique en traction monoasine dans les exploitations agricoles du Nord-Cameroun. Cas du village de Mafa Kilda. Diplôme Ingénieur agronome, Fasa, université de Dschang, Cameroun, 59 p. + annexes.

2. ARDITI C., 1999. Paysans sara et éleveurs arabes dans le sud du Tchad : du conflit à la cohabitation ? In : Baroin C., Boutrais éds, L'homme et I'animal dans le bassin du lac Tchad. Paris, France, IRD, p. 555-574

3. BLANC F., LE MASSON C., LE MASSON A., REMAYEKO A., LE GALL F., LHOSTE P., 1995. Les contraintes au développement de l'élevage bovin en savane humide : I'exemple des Peuls Mbororo en République centrafricaine. Revue mond. Zootech., 82 : 69-77.
4. BONIS CHARANCLE J.M., 2000. Etude de faisabilité en vue de I'externalisation du volet zootechnique du Dpgt. Garoua, Cameroun, Sodécoton, Dpgt, 58 p.

5. CFDT, 1965. La culture attelée dans la zone cotonnière du NordCameroun. Mach. agric. trop., $11: 3-11$.

6. CUVIER L., 1999. Etude des pratiques et des stratégies paysannes de traction animale dans la zone cotonnière du Nord-Cameroun : cas du terroir de Mafa-Kilda. Mémoire DESS productions annimales en régions chaudes. Montpellier, France, Cirad-emvt, 82 p. + annexes.

7. DJAMEN N.P., HAVARD M., DJONNEWA A., 2001. Vers une démarche d'aide à la décision adaptée aux exploitations agricoles du Nord-Cameroun : le conseil de gestion. In : Second comité scientifique du Prasac, Maroua, Cameroun, 5-9 février 2001, 15 p. 
8. DONGMO NGOUTSOP A.L., 1999. Pratiques et stratégies paysannes de traction animale en zone cotonnière du Nord-Cameroun : cas du terroir de Mowo. Diplôme Ingénieur agronome, Fasa, université de Dschang, Cameroun, 121 p. + annexes.

9. DOUNIAS I., 1998. Modèles d'action et organisation du travail pour la culture cotonnière : cas des exploitations agricoles du bassin de la Bénoué au Nord-Cameroun. Thèse Doct. Sciences agronomiques, Ina Paris-Grignon, France, 208 p. + annexes.

10. DROMARD P., 1986. Les résultats de la campagne agricole 1985-86. Evaluation de l'impact de la Sodécoton sur les paysans. Projet Centre Nord. Garoua, Cameroun, Sodécoton, 76 p.

11. DRONNE M., 1969. Rapport d'exécution de l'opération bœufs 19681969. Paris, France, Bdpa, 26 p.

12. DUGUE P., 1998. Flux de biomasse et gestion de la fertilité à l'échelle des terroirs. Etude de cas au Nord-Cameroun et essai de généralisation aux zones de savanes. Montpellier, France, Cirad-tera, 72 p. (Cirad-tera $n^{\circ}$ 29/98)

13. EBANGI A.L., VALL E., 1998. Phenotypic characterization of draft donkeys within the Sudano-Sahelian zone of Cameroon. Revue Elev. Méd. vét. Pays trop., 51: 327-334.

14. FOURNIER A., 1974. La culture attelée et l'association agricultureélevage dans la province du Nord-Cameroun : bilan d'une innovation technologique en milieu rural traditionnel soudano-sahélien. Thèse Doct., Ecole pratique des hautes études, Paris, France, 380 p.

15. GEORGES M., 1965. La culture attelée et la modernisation rurale dans le Nord Cameroun. Paris, France, Bdpa, 318 p.

16. HAVARD M., ENAM J., ABAKAR O., 2000. Les exploitations agricoles dans les terroirs de référence du Prasac au Cameroun. Résultats de l'enquête exhaustive réalisée entre mars et mai 2000. Garoua, Cameroun, Prasac, Délégation nationale, 25 p.

17. HAVARD M., LE THIEC G., VALL E., 1998. Stock number and use of animal traction in sub-Saharan French-speaking Africa. Agric. Mech. Asia, Afr. Lat. Am., 29: 9-14.

18. KEMTSOP TCHINDA G.A., 1999. Fabrication des agro-équipements de traction animale dans la province du Nord Cameroun : place et rôle de I'artisanat du fer. Diplôme Ingénieur agronome, Fasa, université de Dschang, Cameroun, 94 p. + annexes.

19. KENIKOU MOUNKANA C., 2000. Les marchés financiers ruraux. Quelles particularités pour les exploitations agricoles des provinces du Nord et de l'Extrême-Nord du Cameroun. DEA Sciences de gestion, Fseg, université de Ngaoundéré, Cameroun, 136 p. + annexes.

20. LANDAIS E., 1980. L'élevage bovin dans les zones tropicales du sud du Tchad. In : Actes Colloque international sur les recherches de l'élevage bovin en zone tropicale humide, Bouaké, Côte d'Ivoire, 18-22 avril 1977. Paris, France, lemvt, p. 589-599.

21. LANDAIS E., LHOSTE P., 1990. L'association agriculture-élevage en Afrique intertropicale : un mythe techniciste confronté aux réalités du terrain. Cah. Sci. Hum., $26: 217-235$.

22. LAURENT J.-C., 1990. Appui à la cellule culture attelée au projet de développement rural de la zone soudanienne. Projet « Groupement de dépense sanitaire »(Gds). Paris, France, Bdpa-Scetagri, 50 p. + annexes.

23. LE THIEC G., 1994. Le développement de la traction animale en Centrafrique. Montpellier, France, Cirad-sar, 43 p. (Rapport n 106/94)

24. LE THIEC G. coord., 1996. Agriculture africaine et traction animale. Montpellier, France, Cirad, 355 p. (Coll. Techniques)

25. MAZOYER M., ROUDART L., 1998. Histoire des agricultures du monde. Du néolithique à la crise contemporaine. Paris, France, Seuil, $530 \mathrm{p}$.

26. NGUYEN G., 1999. Le financement de I'agriculture au NordCameroun. Rapport de mission (Garoua, 1-9 mai 1999). Montpellier, France, Cirad-tera, 11 p. + annexes. (Cirad-tera n 40/99)
27. ONDR, 1992. Rapport annuel. Zone soudanienne. Campagne 19911992. Moundou, Tchad, Ondr, Sous-direction de la zone soudanienne, $112 \mathrm{p}$.

28. RAUBEC S., 2001. Le financement de la traction animale en zone de savane cotonnière du Nord-Cameroun dans un contexte de libéralisation. Montpellier, France, Cnearc, 209 p. + annexes.

29. RODRIGUEZ M., ANGEL G., 1992. Bilan et perspectives de la mécanisation agricole au Tchad. Paris, France, Gret, $149 \mathrm{p}$.

30. ROESCH M., VALL E., KENIKOU MOUNKAMA C., HAVARD M. 2002. Recettes, dépenses et crédits, comment accorder les rythmes? Ce que peut apporter le Conseil d'exploitation à la gestion de la trésorerie des ménages agricoles et aux institutions de microfinance. In : Le financement de l'agriculture familiale dans un contexte de libéralisation quelle contribution de la microfinance ? Dakar, Sénégal, 21-24 janvier 2002. Montpellier, France, Cirad-tera. (Sous presse)

31. ROUPSARD M., 1984. Le point sur la culture attelée et la motorisation au Nord-Cameroun. Cah. Orstom, Sér. Sci. Hum., 20 613-631.

32. SEIGNOBOS C., TOURNEUX H., HENTIC A., PLANCHENAULT D., 1987. Le poney du Logone. Maisons-Alfort, France, lemvt, 200 p. (Coll. Etudes et synthèses $n^{\circ} 23$ )

33. SODECOTON, 2001. Rapport semestriel de mai à octobre 2001. Campagne agricole 01/02. Garoua, Cameroun, Sodécoton, Dpa, 50 p. + annexes.

34. STARKEY P., 1993. La traction animale au Tchad : politiques et approches. N'djaména, Tchad, Oxfam, 65 p.

35. TACHER G., LACHAUX P., NICOLAS F., 1971. Les bovins de culture attelée au Tchad. In : Colloque Elevage, N'Djaména, Tchad, 8-13 décembre 1969. Maisons-Alfort, France, lemvt, p. 252-267.

36. TCHINSAHBE PABAME I., 2002. Comparaison des performances en champ des sarcleuses monoasine Attila et Sodécoton sur les parcelles paysannes de cotonnier dans le village de Gadas (Extrême-Nord du Cameroun). Diplôme Ingénieur agronome, Fasa, université de Dschang, Cameroun, 62 p. + annexes.

37. VALL E., 1996. Capacités de travail, comportement à l'effort et réponses physiologiques du zébu, de l'âne et du cheval au NordCameroun. Thèse Sciences agronomiques, Ensam, Cirad-emvt, Montpellier, France, $418 \mathrm{p}$.

38. VALL E., 1997. La traction animale en République centrafricaine synthèse bibliographique. Perspectives de recherche-développement dans le cadre du Prasac. Rapport de mission 26 octobre - 1 novembre 1996. Montpellier, France, Cirad-emvt, $44 \mathrm{p}$

39. VALL E., 2000. Compte rendu de mission au Tchad, 18-28 septembre 2000. Djaména, Tchad, Prasac, 12 p.

40. VALL E., DJAMEN P., 2002. Construction d'une méthodologie de conseil à l'agro-équipement de traction animale pour les exploitations agricoles du Nord-Cameroun. In : CR 3 e Sémin. Inra/Cirad, Modélisation du fonctionnement des troupeaux, Verrière, France, 17-18 décembre 2001. Montpellier, France, Cirad-emvt, p. 89-100.

41. VALL E., HUGUENOT S., 2001. Maîtrise des adventices par le sarclage mécanique précoce répété dans les systèmes de culture de la zone de savane cotonnière du Nord-Cameroun. In : Actes $18^{\mathrm{e}}$ Conf. Columa, Journées internationale sur la lutte contre les mauvaises herbes, Toulouse, France, 5-7 décembre 2001. Paris, France, Columa, p. 13051312

42. VANDENDAEL L., 2000. Les paysans du Nord-Cameroun et leurs charrues : un outil, son utilisation et sa fabrication. Grade Ingénieur agronome, FusaGx, Gembloux, Belgique, 84 p. + annexes.

Reçu le 03.02.2003, accepté le 13.03.2003 


\section{Summary}

Vall E., Dongmo Ngoutsop A.L., Abakar O., Meyer C. Animal Draft in the Cotton Savannah New Context in Chad, Cameroon and the Central African Republic. I. Expansion and Role on the Farms

Animal draft has been used for a very long time in sub-Saharan Africa, but it underwent many changes. The Central Africa savannah zone counts about 260,000 animal teams $-40 \%$ of farms are equipped in Chad, $25 \%$ in Cameroon and $10 \%$ in the Central African Republic. Two-oxen systems prevail. In production systems, animal power is primarily used for ploughing and secondarily for maintenance and transport. Animal draft has major agronomic (mechanization, agriculturelivestock integration) and socioeconomic functions. The equipment phase is a strategic time for the farmer. Since 1950, cotton companies have proposed equipment credits and technical aid that highly contributed to animal draft development. Farmers invested a large part of cotton revenues into this technique.

Key words: Animal power - Innovation - Savannah Cotton - Chad - Cameroon - Central Africa Republic.

\section{Resumen}

Vall E., Dongmo Ngoutsop A.L., Abakar O., Meyer C. La tracción animal en el nuevo contexto de las sabanas algodonales de Chad, Camerún y República centroafricana. I. Difusión de la tracción animal y su lugar en las explotaciones

La tracción animal se explota desde hace mucho tiempo en Africa subsahariana, sin embargo, su evolución ha sido grande. La zona de las sabanas de Africa central cuenta con alrededor 260000 yuntas $(40 \%$ de las explotaciones están equipadas en Chad, $25 \%$ en Camerún y $10 \%$ en la República centroafricana). La tracción a dos bovinos es la que domina. En los sistemas de producción, la energía animal se utiliza sobre todo para labrar con carreta y, de forma secundaria, para operaciones de mantenimiento y transporte. La tracción animal tiene funciones agronómicas (mecanización, integración agricultor-cría) y funciones socio económicas importantes. La etapa de obtención del equipo es un momento estratégico en la explotación. Desde 1950 los créditos para equipo y la asistencia técnica propuesta por las sociedades algodonales han contribuido fuertemente al desarrollo de la tracción animal. Los campesinos han invertido una parte importante de los rendimientos del algodón.

Palabras clave: Energía animal - Innovación - Sabana - Algodon - Chad - Camerún - República centroafricana. 